\title{
The primary healthcare network in Lebanon: a national facility assessment
}

Randa Hemadeh, ${ }^{1}$ Ola Kdouh, ${ }^{1}$ Rawan Hammoud, ${ }^{1}$ Tarek Jaber ${ }^{1}$ and Lama A. Khalek ${ }^{1}$

${ }^{1}$ Department of Primary Healthcare, Ministry of Public Health, Beirut, Lebanon (Correspondence to: O. Kdouh: olakdouh@gmail.com).

\begin{abstract}
Background: The assessment of material and human resources, as well as services at healthcare facilities can further our understanding of their capacity to adapt to a people-centred framework.

Aims: To assess health infrastructure, drugs, equipment and human resources in primary healthcare centres (PHCCs) within the Lebanese National Primacy Healthcare Network.

Methods: The study surveyed all 212 primary healthcare centres in the network to assess services, as well as material and human resource availability. The survey was developed by the Ministry of Public Health and administered at each PHCC through face-to-face interviews with the facilities' directors. Data collection took place between December 2017 and January 2018. Descriptive statistics and $\chi^{2}$ tests were used to analyse the collected data.

Results: The majority of PHCCs in the network delivered all services required by the national standards (78\%), and had all basic equipment necessary for the delivery of care (89\%), in addition to viable means of communication (85\%). However, there was a significant shortage of family medicine physicians and nurses. Bivariate analysis highlighted regional disparities between urban and rural areas.

Conclusions: This study can further our understanding of the capacity and ability of healthcare facilities to adapt to a people-centred framework. It provides baseline data that will inform Lebanon in its efforts to strengthen primary health care, and assist donors and local and international nongovernmental organizations in planning interventions and programmes, and better allocation of financial support.

Keywords: facility assessment, health human resources, health services, Lebanon, primary healthcare

Citation: Hemadeh R; Kdouh O; Hammoud R; Jaber T; Khalek LA. The primary health care network in Lebanon: a national facility assessment. East Mediterr Health J. 2020;26(6):700-707. https://doi.org/10.26719/emhj.20.003

Received: 11/10/18; accepted: 25/03/19

Copyright (C) World Health Organization (WHO) 2020. Open Access. Some rights reserved. This work is available under the CC BY-NC-SA 3.o IGO license (https://creativecommons.org/licenses/by-nc-sa/3.o/igo).
\end{abstract}

\section{Introduction}

People-centred healthcare systems can reduce healthcare costs, and potentially lead to improved population health outcomes, access to care, and patient satisfaction (1). These systems aim to empower patients, families and communities, providing them with healthcare services while respecting their needs, preferences and expectations (1). Reorienting the model of care towards preventive ambulatory services is essential to move towards a people-centred healthcare system (1). Therefore, countries striving to develop a people-centred system need to strengthen primary healthcare $(\mathrm{PHC})$ and ensure effective service delivery. Crucial to the delivery of services are health infrastructure, drugs and equipment, and trained health human resources (2); assessment of which can further our understanding of the capacity, and ability of healthcare facilities to adapt to a people-centred framework. This would also provide policy-makers with data and empirical evidence that can guide programme design, implementation and monitoring (3).

In Lebanon, public spending on health constitutes only $5.8 \%$ of the total government spending (4); allocations to the Ministry of Public Health $(\mathrm{MoPH})$ from the government budget decreased from 5.9\% in 2005 to $3.4 \%$ in 2012 (4); and given the Lebanese healthcare system's orientation towards curative care, only $5 \%$ of the MoPH budget is allocated to preventive PHC services (5). These challenges are exacerbated by the ongoing political turmoil in the region, culminating in the Syrian refugee crisis, and have had a massive impact on the Lebanese healthcare system in general and $\mathrm{PHC}$ sector in particular, as Syrian refugees constitute $47 \%$ of all those who access care through the National PHC Network $(6,7)$. As strengthening PHC has always been a key pillar of the national health strategy, Lebanon was still able to move towards people-centred care in recent decades (6).

The MoPHestablished its National PHC Network in 1996, through which it aimed to regulate and maintain quality of care and effective service delivery at PHC centres (PHCCs) (8). This network currently comprises 226 PHCCs; most of which are affiliated with nongovernmental organizations (NGOs) and municipalities. It serves $>1$ million people annually. Through its delivery of a comprehensive range of $\mathrm{PHC}$ services at reduced rates, it aims to improve access to effective, quality health care, particularly among the most vulnerable. Complementing the establishment of the network, the MoPH targets community needs through the integration of noncommunicable disease management in PHC and launching of the national mental health 
programme $(9,10)$. In 2009, the MoPH initiated a national primary healthcare accreditation programme, leading to the accreditation of 52 PHCCs as of June 2018. Furthermore, in 2016, the MoPH took a major step towards universal health coverage as it collaborated with the World Bank to subsidize a benefits package delivered through 75 PHCCs, for 150000 vulnerable Lebanese citizens; particularly those affected by the Syrian refugee crisis (11).

However, reliable and comprehensive data on the functional capacities and the state of material and human resources in PHCCs are still unavailable. As the $\mathrm{MoPH}$ looks to advance people-centred care and expand its universal health coverage programme, a better understanding of the sector's infrastructure and resources is integral to guiding short- and long-term reforms and investment efforts.

Here, we surveyed PHCCs in Lebanon to assess services, as well as material and human resource availability, and explored facility characteristics associated with the fulfilment of national PHC standards. This study is believed to be the first to document comprehensive data on the state of material and health human resources within the National PHC Network, and assess the availability and readiness of services provided by the PHCCs.

\section{Methods}

\section{Objectives}

This study aimed to provide a detailed account of the current state of the National Primary Healthcare Network in Lebanon. Specifically, it assessed availability of health infrastructure, health human resources, and availability of primary healthcare services, and service readiness, at the PHCCs within the National Primary Healthcare Network. Additionally, it explored facility characteristics associated with the fulfilment of staffing and infrastructure national standards.

\section{Data collection}

Data collection took place in Lebanon between December 2017 and January 2018. A survey was administered at each PHCC through interviews with the PHCC directors. Responses were validated through direct observation at the facilities by trained public health officers employed at the $\mathrm{MoPH}$. All 212 centres that were part of the National Primary Healthcare Network at the time were targeted and included in the study.

\section{Facility assessment tool}

Development of the facility assessment tool was guided by the World Health Organization Service Availability and Readiness Assessment (SARA) (12) and other internal assessment tools at the MoPH. An initial draft was developed, translated into Arabic, and then back translated into English at the MoPH. It was reviewed and validated by the technical team at the Primary Healthcare Department. The tool was piloted in 2 stages. First, it was administered in 2 PHCCs that offered all services included within the tool. The main pilot findings were related to the flow of the questionnaire and the data collection process. The tool was then modified in accordance with the pilot observations. Afterwards, the modified version was piloted again and the tool was validated and adopted. The survey tool assesses the availability of health human resources, infrastructure, and services, in addition to the readiness of services at the PHCCs. Readiness refers to the capacity of a PHCC to deliver the service and is measured through tracer items that include trained staff, infrastructure, and the availability of written guidelines, equipment and commodities (12).

\section{Availability of health human resources}

The availability of health human resources refers to the physical presence of the following staffing categories: (1) part-time and full-time physicians: general practitioners (GPs), family physicians, gynaecologists, dentists, cardiologists, paediatricians, nephrologists, urologists, endocrinologists, orthopaedists, pulmonologists, ophthalmologists, gastroenterologists, psychiatrists, dermatologists, ear, nose and throat specialists, rheumatologists, and neurologists; (2) part-time and full-time supporting staff: registered nurses, assistant nurses, midwives, social workers/mental health social workers, psychologists, radiologists, laboratory technicians, dieticians, pharmacist assistants, and pharmacists; and (3) part-time and fulltime administrative staff: administrative directors, data entry staff, information technology staff, and secretaries.

According to the Lebanese national PHC standards, all PHCCs should recruit the following clinical staff: GP/family physician, paediatrician, gynaecologist, cardiologist/endocrinologist, dentist, and registered nurse. The availability of health human resources was assessed through: (1) percentage of PHCCs employing all aforementioned clinical staff; and (2) percentage of PHCCs employing all medical staff as required by the national standards with the exception of a registered nurse.

\section{Availability of health infrastructure}

The availability of infrastructure refers to the physical presence of the following: (1) basic amenities: backup electrical supply, fire extinguisher, complaint box, access to sanitation facilities, and accessibility equipment; (2) basic equipment: thermometer, stethoscope, adult scale, child scale, blood pressure apparatus, and lighting source; (3) means of communication: landline/cellular telephone, computer, information system, and access to intranet and internet; and (4) infection control: written guidelines on infection control, disinfectants, soap and running water or alcohol-based rubs, space for sterilization, latex gloves, waste receptacle, and sink in each clinic. The availability of health infrastructure was assessed through the percentage of $\mathrm{PHCC}$ reporting the presence of all the infrastructure requirements.

\section{Availability and readiness of services}

The availability of services refers to the delivery of the following services at a facility: (1) family medicine (FM)/ general consultation services; (2) dental services; (3) pae- 
diatric services; (4) reproductive, maternal, and newborn health services; (5) noncommunicable disease management; (6) mental health services; (7) diagnostic imaging services; (8) basic laboratory services; and (9) pharmaceutical services. The availability of PHC services was assessed through the percentage of PHCCs administering the above-mentioned services.

Service readiness was evaluated for the 5 basic services required by the national PHC standards: (1) FM/general consultation services; (2) dental services; (3) paediatric services; (4) reproductive, maternal and newborn health services; and (5) noncommunicable disease management. A score comprising availability of trained staff, infrastructure, written guidelines, servicespecific equipment and commodities was calculated for each PHCC. This score was based on the national PHC standards, and developed following consultations with programme coordinators at the Primary Healthcare Department. Centres were then classified as either ready or in progress in each of the aforementioned services.

\section{Facility characteristics}

The fulfilment of staffing and health infrastructure national standards was compared across the following facility characteristics: governorate, settlement type, accreditation status, and international NGO support. Lebanon comprises 8 different governorates. Settlement type refers to the location of the PHCCs in an urban or rural setting. Accreditation status refers to whether the PHCCs were accredited at the time of the study. Finally, international NGO support indicates whether the PHCCs received support from international NGOs, which can include capacity building, equipment, and financial aid.

\section{Data analysis}

Descriptive statistics, mainly frequencies and percentages, for our categorical facility characteristics were reported. The availability of services at the PHCCs was reported using bar plots. $\chi^{2}$ tests were conducted to assess correlation between the fulfilment of staffing and health infrastructure requirements and facility characteristics. Statistical significance was set at $P<0.05$. Statistical analyses were conducted on RStudio version 1.1.453.

\section{Ethical considerations}

The facility survey was administered as part of the MoPH's monitoring and evaluation activities. Required administrative authorization to use the data for research was obtained from the concerned parties at the Lebanese MoPH. Heads of PHCCs were informed about the MoPH's initiative and informed consent to use the data for research was obtained from all participating heads of PHCCs before administering the survey.

\section{Results}

\section{Primary Healthcare Network}

There were 212 PHCCs within the MoPH Primary Healthcare Network distributed across all Lebanese gover- norates (Table 1). Mount Lebanon included the largest number of PHCCs $(\mathrm{n}=55,25.9 \%)$ while the lowest was recorded in Beirut $(n=14,6.6 \%)$. Additionally, more than half of the PHCCs were located in rural areas $(\mathrm{n}=125$, $59.0 \%)$. Seventeen $(8.0 \%)$ of the PHCCs were accredited through the national $\mathrm{PHC}$ accreditation programme.

\section{Availability of health infrastructure}

On average there were 6 clinics in every PHCC, with the minimum and maximum number of clinics across the facilities being 2 and 18, respectively. The average hours of operation in the weekdays and weekends for all facilities were 7.49 (standard deviation $=3.15$ ) and 4.75 (4.19), respectively. One hundred and eighty-eight (88.7\%) PHCCs reported availability of all 6 types of basic equipment; $181(85.4 \%)$ fulfilled all means of communication requirements; 103 (48.5\%) fulfilled basic amenities requirements; $84(39.6 \%)$ fulfilled infection control requirements; and 57 (26.9\%) fulfilled all infrastructure requirements.

\section{Availability of health human resources}

Among health human resources, there were 484 nurses within the National Primary Healthcare Network, 88.0\% of whom were employed on a full-time basis. Overall, 122 PHCCs (57.6\%) employed all medical staff as per the PHC national standards, and 147 PHCCs (69.3\%) employed all medical staff with the exception of a registered nurse. The most widely employed specialists at PHCCs were cardiologists/endocrinologists (employed by $91.5 \%$ of PHCCs), followed by paediatricians (91.0\%) and gynaecologists (88.7\%); taking into account that most were part-timers

\begin{tabular}{|c|c|c|}
\hline \multicolumn{3}{|l|}{ Table 1 PHCC characteristics } \\
\hline Characteristics & n & Valid percentage (\%) \\
\hline \multicolumn{3}{|l|}{ Governorate } \\
\hline Beirut & 14 & 6.6 \\
\hline Mount Lebanon & 55 & 25.9 \\
\hline North & 30 & 14.2 \\
\hline Akkar & 22 & 10.4 \\
\hline Baalbek-Hermel & 18 & 8.5 \\
\hline Bekaa & 19 & 9.0 \\
\hline South & 27 & 12.7 \\
\hline Nabatieh & 27 & 12.7 \\
\hline \multicolumn{3}{|l|}{ Accreditation } \\
\hline Yes & 17 & 8.0 \\
\hline \multicolumn{3}{|l|}{ Settlement type } \\
\hline Urban & 87 & 41.0 \\
\hline Rural & 125 & 59.0 \\
\hline \multicolumn{3}{|l|}{ Facility type } \\
\hline PHCC & 199 & 93.9 \\
\hline PHCC within hospital OPD & 13 & 6.1 \\
\hline \multicolumn{3}{|l|}{ International NGO support } \\
\hline Yes & 95 & 44.8 \\
\hline Total & 212 & 100.00 \\
\hline
\end{tabular}

$\mathrm{NGO}=$ nongovernmental organization; $\mathrm{OPD}=$ outpatient department; $\mathrm{PHCC}=$ primary healthcare centre. 


\begin{tabular}{lcc}
\hline $\begin{array}{l}\text { Table } 2 \text { Number of PHCCs employing specific health human } \\
\text { resources }\end{array}$ & n & Valid percentage (\%) \\
\hline $\begin{array}{l}\text { Health human resources } \\
\text { category }\end{array}$ & 169 & 79.7 \\
Generalist & 29 & 13.7 \\
Family physician & 193 & 91.0 \\
Paediatrician & 188 & 88.7 \\
Gynaecologist & 180 & 84.9 \\
Dentist & 194 & 91.5 \\
Cardiologist/endocrinologist & 165 & 77.8 \\
Registered nurse & 131 & 61.8 \\
Assistant nurse & 66 & 31.1 \\
Midwife & 79 & 37.3 \\
Social worker/mental health & 93 & 43.9 \\
social worker & 135 & 63.7 \\
Pharmacist assistant & 187 & 88.2 \\
Pharmacist & 128 & 60.4 \\
Administrative director & 68 & 32.1 \\
Data entry staff & 91 & 42.9 \\
IT & $\mathbf{2 1 2}$ & $\mathbf{1 0 0}$ \\
Secretary & & \\
Total number of PHCCs & information technology; PHCC = primary healthcare centre.
\end{tabular}

who worked in more than one PHCC at a time (Table 2). The least commonly employed staff were FM physicians (13.7\%), midwives (31.1\%) and IT staff (32.1\%).

\section{Availability and readiness of services}

Overall, there were 165 PHCCs $(77.8 \%)$ that offered the 5 main services required by the national standards (Figure 1). Two hundred and eight (98.1\%) PHCCs offered paediatric services; 206 (97.2\%) offered pharmaceutical services; and 200 (94.3\%) each offered general medical services and noncommunicable disease management. Only 78 (36.8\%) and 67 (31.6\%) PHCCs offered mental health and diagnostic services. In total, 22 PHCCs (10.4\%) offered all 9 services including diagnostic imaging, laboratory, pharmaceutical and mental health services.

Service readiness was highest for noncommunicable disease management $(n=129,64.5 \%)$, followed by general medical ( $n=108,54.0 \%)$, paediatric $(n=91,43.8 \%)$, dental $(n=68,35.8 \%)$ and reproductive and maternal services $(n$ $=55,27.6 \%)$.

\section{Facility characteristics associated with staffing and health infrastructure requirements}

The PHCC governorate was significantly associated with fulfilling staffing requirements $(P=0.006)$ (Table 3$)$. In fact, the greatest proportion of centres that fulfilled these requirements was observed in Mount Lebanon (76.4\%) and Beirut $(71.4 \%)$. In Akkar, this proportion reached $36.4 \%$, the lowest among Lebanese governorates. Consistently, a greater proportion of PHCCs in urban areas $(73.6 \%)$ fulfilled the staffing requirements as compared to rural areas (46.4\%). Additionally, the majority of accredit- ed centres (88.2\%) fulfilled the staffing requirements as opposed to $54.9 \%$ among nonaccredited PHCCs. This difference in proportion was significant $(P=0.008)$. International NGO support and accreditation status were both significantly associated with fulfilling health infrastructure requirements ( $P=0.044$ and 0.001 , respectively).

\section{Discussion}

Overall, $77.8 \%$ of PHCCs within the network offered all 5 main PHC services. However, their readiness for the delivery of these services was low. This was mainly attributed to the unavailability of advanced medical equipment, and the absence of written clinical guidelines that informed future quality improvement, capacity building, and resource provision efforts. Juxtaposed to the above, the majority of PHCCs in the network had all the basic equipment necessary for the delivery of care $(88.7 \%)$, and viable means of communication (85.4\%), including internet access and a backup electrical supply. These results are consistent with the MoPH's efforts in strengthening PHCCs through the provision of medical supplies and equipment, and the implementation of its electronic health information system across its PHC network.

Concerning health human resources, there was a significant shortage of FM physicians at the PHCCs. In Lebanon, this shortage can be attributed to several barriers inherent to the educational system, including the scarcity of FM programmes (13), and the low prestige associated with the profession in low- and middleincome countries (14). This is consistent with studies on FM in the Middle East, which have expanded on the low number of FM training programmes (15), and reported a low FM physician to population ratio across Arab countries (16). Additionally, a recent study conducted in Saudi Arabia revealed a significant shortage of FM physicians, employed in only $7 \%$ of all PHCs in the country (17). In efforts to reinforce an FM model of care, the $\mathrm{MoPH}$ in Lebanon developed and subsidized a bridging programme for GPs working in PHCCs to transition to FM specialists. GPs enrolled in the programme were also committed to working in the PHC sector following receipt of their degrees. In line with this initiative, further interministerial programmes to reskill specialists in FM are needed to advance the FM model of care. However, in light of limited financial resources in the PHC sector in general and the $\mathrm{MoPH}$ in particular, the ability to initiate and sustain such programmes remains unclear.

Similarly, our study uncovered a shortage of nurses in PHCCs. More than $20 \%$ of surveyed PHCCs did not employ a registered nurse as required by the national standards. These results are consistent with previous studies on the nursing workforce in Lebanon, which reported a nurse to population ratio of 2.72 per 1000 as compared with 4.05, 4.55 and 4.87 in Jordan, Kuwait and Saudi Arabia, respectively $(18,19)$. There are several barriers that might account for this, including low enrolment in nursing programmes, and migration of the nursing workforce primarily to Gulf countries $(20,21)$. 


\begin{tabular}{|c|c|c|c|c|c|c|}
\hline Variable & $\begin{array}{c}\text { Staffing } \\
\text { requirements } \\
\text { fulfilled, } \mathrm{n}(\%)\end{array}$ & $\begin{array}{c}\text { Staffing } \\
\text { requirements not } \\
\text { fulfilled, } \mathbf{n}(\%)\end{array}$ & $P$ & $\begin{array}{l}\text { Infrastructure } \\
\text { requirements } \\
\text { fulfilled, } \mathrm{n}(\%)\end{array}$ & $\begin{array}{l}\text { Infrastructure } \\
\text { requirements not } \\
\text { fulfilled, } \mathbf{n}(\%)\end{array}$ & $P$ \\
\hline \multicolumn{7}{|l|}{ Governorate } \\
\hline Beirut & $10(71.4)$ & $4(28.6)$ & \multirow{8}{*}{0.006} & $2(14.3)$ & $12(85.7)$ & \multirow{8}{*}{0.309} \\
\hline Mount Lebanon & $42(76.4)$ & $13(23.6)$ & & $14(25.4)$ & $41(74.6)$ & \\
\hline North & $19(63.3)$ & $11(36.7)$ & & $9(30.0)$ & $21(70.0)$ & \\
\hline Akkar & $8(36.4)$ & $14(63.6)$ & & $4(13.6)$ & $18(86.4)$ & \\
\hline Baalbek-Hermel & $11(61.1)$ & $7(38.9)$ & & $3(16.7)$ & $15(83.3)$ & \\
\hline Bekaa & $8(42.1)$ & $11(57.9)$ & & $4(21.1)$ & $15(78.9)$ & \\
\hline South & $13(48.2)$ & $14(51.8)$ & & $12(40.7)$ & $15(59.3)$ & \\
\hline Nabatieh & $11(40.7)$ & $16(56.3)$ & & $9(33.3)$ & $18(66.7)$ & \\
\hline \multicolumn{7}{|l|}{ Settlement type } \\
\hline Rural & $58(46.4)$ & $67(53.6)$ & \multirow{2}{*}{0.001} & $33(24.8)$ & $92(75.2)$ & \multirow{2}{*}{0.848} \\
\hline Urban & $64(73.6)$ & $23(26.4)$ & & $24(27.6)$ & $63(72.4)$ & \\
\hline \multicolumn{7}{|l|}{ Accreditation status } \\
\hline No & $107(54.9)$ & $88(45.1)$ & \multirow{2}{*}{0.008} & $46(23.1)$ & $149(76.9)$ & \multirow{2}{*}{0.001} \\
\hline Yes & $15(88.2)$ & $2(11.7)$ & & $11(58.8)$ & $6(41.2)$ & \\
\hline \multicolumn{7}{|l|}{ NGO support } \\
\hline No & $64(54.7)$ & $53(45.3)$ & \multirow{2}{*}{0.352} & $25(21.4)$ & $92(78.6)$ & \multirow{2}{*}{0.044} \\
\hline Yes & $58(61.1)$ & $37(38.9)$ & & $32(31.6)$ & $63(68.4)$ & \\
\hline
\end{tabular}

Figure 1 Availability of services at primary healthcare centres in Lebanon.

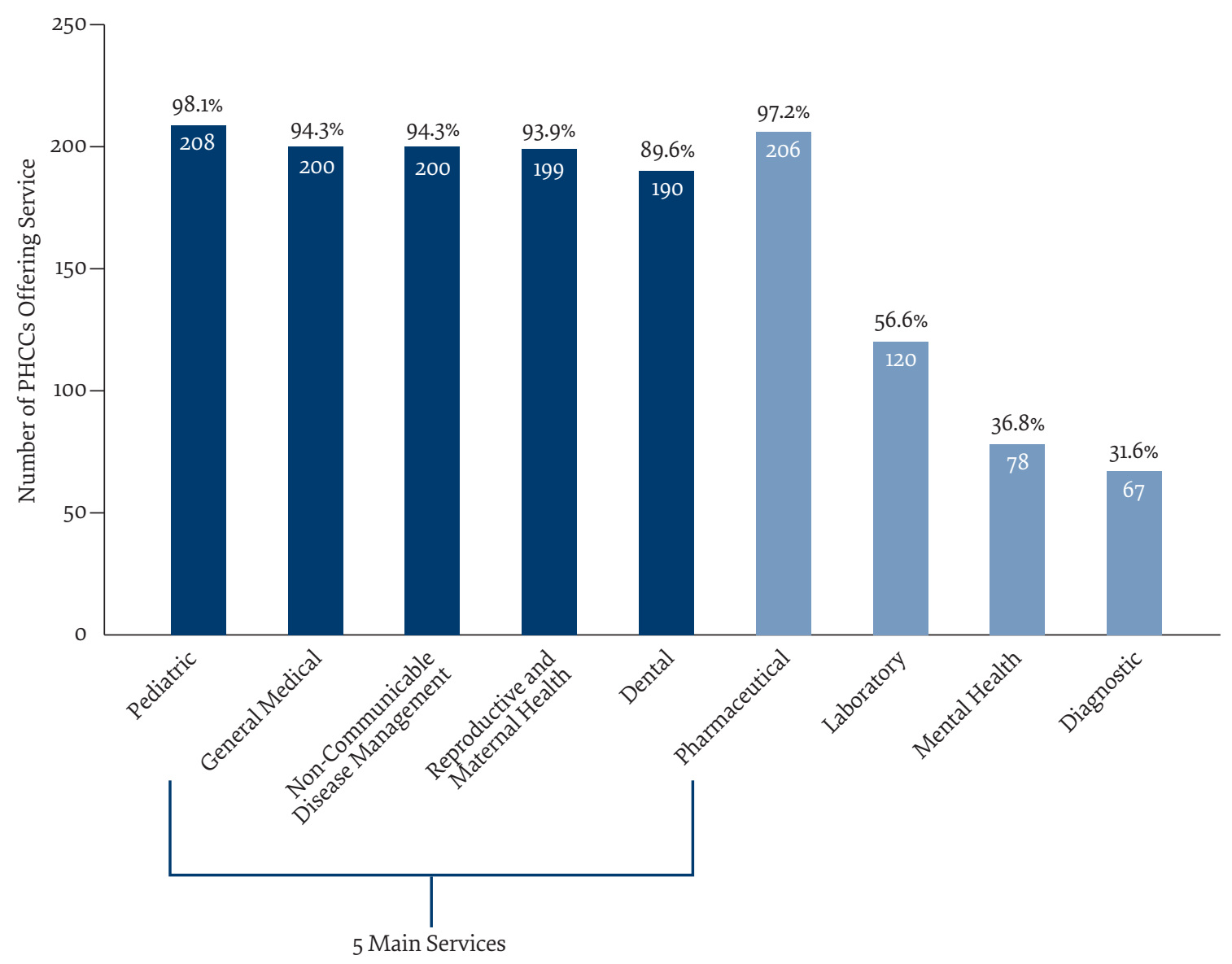


Additionally, the PHC sector's competition with hospitals and larger medical centres, which employed $>85 \%$ of the nursing workforce in Lebanon in 2014 (18), aggravates the issue. In response, the MoPH regularly coordinates with the Order of Nurses and educational institutions to offer nursing students internship opportunities and engage them in the PHCC sector. However, further reform initiatives are warranted to attract nurses to PHCCs through offering them improved working conditions, better career prospects, and greater financial incentives.

The study analysis further explored facility characteristics associated with improved staffing and health infrastructure. It revealed urban-rural disparities in health human resource availability. The proportion of facilities fulfilling staffing requirements was lower in rural than urban areas, indicating an alarming gap, as more than half of the PHCCs in the network are located in a rural setting. These findings are consistent with international and local literature on the barriers to the recruitment and retention of health human resources in rural and underserved areas $(22,23)$. The disparities between urban and rural areas were similarly reported in the United Arab Emirates (24), Jordan (25) and in Morocco (26) where the number of inhabitants per physician varied from 380 in the capital to 6362 in rural areas. This relative shortage in health human resources in rural areas can potentially be addressed through financial incentive systems, such as bonuses and pay increases, in addition to programmes and initiatives securing continuous education, training and professional development for staff (23).

We also found that the fulfilment of infrastructure and equipment standards at the facilities was correlated with international NGO support. In fact, following the Syrian refugee crisis, the MoPH formed a National Health Steering Committee through which United Nations agencies, international NGOs, and other stakeholders coordinated activities, programmes and support (27). The aforementioned result indicates that the MoPH successfully played its role as the leader of the health response by ensuring that the received funds and support were in line with the national PHC standards.

Our study had some limitations. The facility assessment tool did not include sections on service affordability and quality in addition to provider fulltime equivalency and details on outreach activities and referral arrangements, therefore limiting the scope of the analysis. Furthermore, the number of health human resources could not be accurately calculated through the survey, as it did not capture the duplication of part-time staff across healthcare facilities.

\section{Conclusion}

This study provided a comprehensive assessment of materials, human resources and health services at PHCCs in the Lebanese National PHC Network. Study findings can inform local efforts to optimize PHC service provision and move towards a people-centred healthcare system. The study highlighted the need to address urban-rural disparities in human resource availability, strengthen FM as an essential pillar of people-centred care, and empower and expand the nursing workforce in the sector. However, crucial to the implementation of any effort are financial reforms that address the scarcity of funding in the sector through increasing the government's budget allocation to the $\mathrm{MoPH}$, and reprioritizing $\mathrm{PHC}$ within the MoPH's budget allocation. This is also relevant for donors and local and international NGOs, as the identification of gaps within the PHC sector could assist in planning interventions and programmes, and better allocation of equipment, aid and financial support.

Future research should explore discrepancies in resource availability and service provision between urban and rural PHCCs. While our study gave ample description of the PHCCs' internal characteristics, more information on their external interactions is needed. As such, an assessment geared towards the interaction of the facilities with their environment, including the wider healthcare system and the community at large, is warranted.

\section{Acknowledgements}

The authors acknowledge Michelle Mansour for her contribution to the development of the facility assessment tool and the data collection process. Additionally, the authors acknowledge the MoPH Director General Dr. Walid Ammar for his guidance, Global Health Team of Experts for their technical assistance, and the Primary Healthcare Department team at the MoPH for their support in survey implementation.

Funding: None.

Competing interests: None declared.

\section{Réseau de soins de santé primaires au Liban : évaluation nationale des établissements Résumé \\ Contexte : L'évaluation des ressources matérielles et humaines, ainsi que des services dans les établissements de soins de santé peut aider à mieux comprendre leur capacité à s'adapter à un cadre centré sur la personne.}

Objectifs : La présente étude visait à évaluer les infrastructures de santé, les médicaments, le matériel et les ressources humaines dans les centres de soins de santé primaires du réseau national de soins de santé primaires du Liban. 
Méthodes : L'étude s'est intéressée aux 212 centres de soins de santé primaires que compte le réseau, afin d'en évaluer les services ainsi que la disponibilité des ressources matérielles et humaines. L'enquête a été mise au point par le ministère de la Santé publique et menée dans chaque centre de soins de santé primaires lors d'entretiens en présentiel avec les directeurs des établissements. La collecte des données a eu lieu entre décembre 2017 et janvier 2018. Des statistiques descriptives et des tests du $\chi^{2}$ ont été utilisés pour analyser les données collectées.

Résultats : La majorité des centres du réseau assuraient tous les services requis conformément aux exigences nationales (78 \%) et possédaient tout le matériel de base nécessaire pour dispenser les soins (89\%), en plus de moyens de communication viables ( $85 \%$ ). Néanmoins, une pénurie importante de médecins et de personnels infirmiers en médecine familiale a été relevée. Une analyse bivariée a mis en évidence des disparités régionales entre les zones urbaines et rurales.

Conclusions : La présente étude permet d'approfondir notre compréhension de la capacité et de l'aptitude des établissements de soins de santé à s'adapter à un cadre centré sur la personne. Elle fournit des données de référence qui guideront le Liban dans ses efforts de renforcement du système de soins de santé primaires et qui aideront les donateurs et les organisations non gouvernementales locales et internationales à planifier leurs interventions et leurs programmes, ainsi qu'à mieux affecter leur soutien financier.

$$
\begin{aligned}
& \text { شبكة الرعاية الصحية الأولية في لبنان: تقييم المر افق الوطنية } \\
& \text { رندة حماده، علا قدوح، روان حمود، طارق جابر، لمى عبد الخالق } \\
& \text { الخلاصة }
\end{aligned}
$$

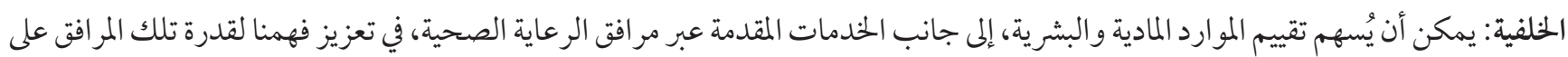

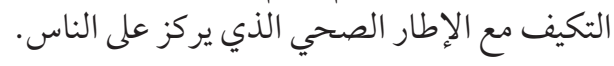

الأهداف: هدفت هذه الدراسة إلى تقييم البنية التحتية الصحية، والأدوية، والمعدات، والموارد البشرية في مراكز الرعاية الصحية الأولية التابعة لشبكة الرعاية الصحية الأولية الوطنية اللبنانية.

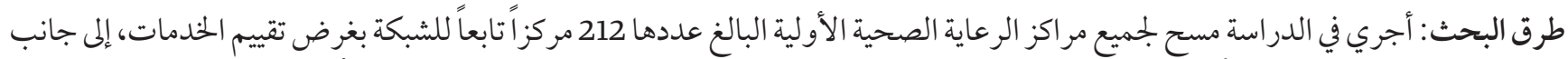

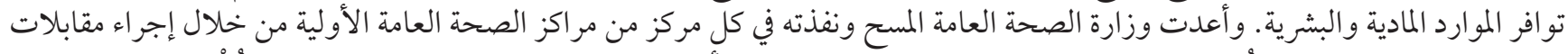

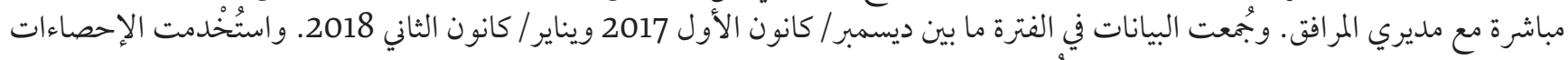

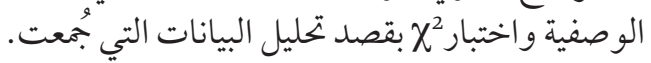

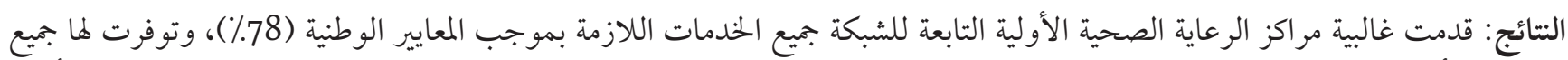

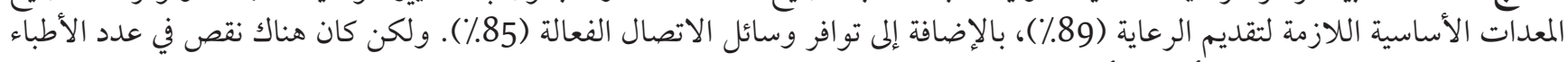

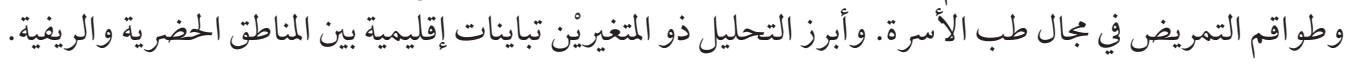

الاستنتاجات: يمكن أن تسهم هذه الدراسة في تعزيز فهمنا لقدرة وكفاءة مرافق الرعاية الصحية على التكيف مع الإطار الذي يركز على النى الناس.

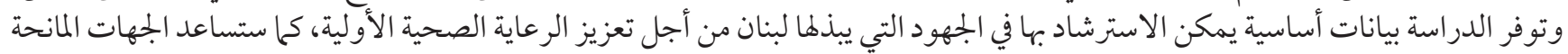

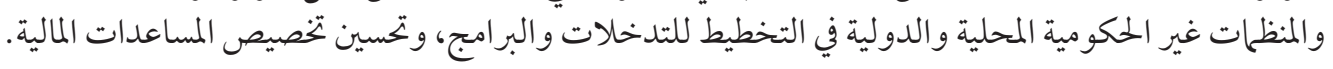

\section{References}

1. Framework on integrated, people-centred health services: report by the Secretariat. Geneva: World Health Organization; 2016 (https://apps.who.int/iris/handle/10665/252698, accessed 8 January 2020).

2. Oyekale AS. Assessment of primary health care facilities' service readiness in Nigeria. BMC Health Serv Res. 2017 Mar 1;17(1):172. http://dx.doi.org/10.1186/s12913-017-2112-8 PMID:28249578

3. O'Neill K, Takane M, Sheffel A, Abou-Zahr C, Boerma T. Monitoring service delivery for universal health coverage: the Service Availability and Readiness Assessment. Bull World Health Organ. 2013 Dec 1;91(12):923-31. http://dx.doi.org/10.2471/BLT.12.116798 PMID:24347731

4. World Bank. Lebanon economic monitor. The great capture. 2015. Washington DC: World Bank; 2015 (http://documents.albankaldawli.org/curated/ar/397721468185952923/pdf/101022-WP-PUBLIC-disclosed-11-18-4am-DC-time-11am-Beirut-Box393257BThe-World-Bank-LEM-Fall-2015.pdf, accessed 8 January 2020).

5. Public health: overview of the health sector. Council for Development and Reconstruction; 2013 (http://www.cdr.gov.lb/eng/progress_reports/pr102013/Epub.pdf, accessed 8 January 2020).

6. Ammar W, Kdouh O, Hammoud R, Hamadeh R, Harb H, Ammar Z, et al. Health system resilience: Lebanon and the Syrian refugee 
crisis. J Global Health. 2016 Dec;6(2):020704. http://dx.doi.org/10.7189/jogh.06.020704 PMID:28154758

7. EPHRP DASHBOARD Semi-Annual, 2018. Beirut: Ministry of Public Health; 2018 (https://www.moph.gov.lb/userfiles/files/Programs\%26Projects/Emergency\%20Primary\%20Health\%20Care/EPHRP_Dashboard_June2018.pdf, accessed 8 January 2020).

8. Ammar W. Health beyond politics. World Health Organization, Eastern Mediterranean Regional Office; Ministry of Public Health, Lebanon; 2009 (https://www.moph.gov.lb/DynamicPages/download_file/2007, accessed 8 January 2020).

9. Mental health and substance use - prevention, promotion, and treatment - situation analysis and strategy for Lebanon 20152020. Beirut: Ministry of Public Health; 2015 (https://www.moph.gov.lb/en/Pages/6/553/nmhp, accessed 8 January 2020).

10. Integration of non-communicable disease services within primary health care [website]. Beirut: Ministry of Public Health (https://www.moph.gov.lb/en/Pages/6/776/non-communicable-disease-program-primary-health-care, accessed 8 January 2020).

11. Emergency primary health care restoration project towards universal health coverage in collaboration with World Bank [website]. Beirut: Ministry of Public Health (https://www.moph.gov.lb/en/Pages/6/779/universal-health-coverage-project-lebanon, accessed 8 January 2020).

12. Service Availability and Readiness Assessment (SARA): an annual monitoring system for service delivery: Reference manual. Geneva: World Health Organization; 2013 (https://www.who.int/healthinfo/systems/SARA_Reference_Manual_Full.pdf, accessed 8 January 2020).

13. Agreus L, Saab B. International primary care snapshots: Sweden and Lebanon. Br J Gen Pract. 2015 Jan;65(630):28-9. http://dx.doi. org/10.3399/bjgp15X683185 PMID:25548300

14. Puertas EB, Arósquipa C, Gutiérrez D. Factors that influence a career choice in primary care among medical students from high-, middle-, and low-income countries: a systematic review. Rev Panam Salud Publica. 2013 Nov;34(5):351-8. PMID:2455376

15. Abyad A, Al-Baho AK, Unluoglu I, Tarawneh M, Al Hilfy, Thamer Kadum Yousif. Development of family medicine in the Middle East. Fam Med. 2007 Nov-Dec;39(10):736. PMID: 1798741

16. Osman H, Romani M, Hlais S. Family medicine in Arab countries. Fam Med. 2011 Jan;43(1):37. PMID:21213135

17. Al-Khaldi YM, Al-Ghamdi EA, Al-Mogbil TI, Al-Khashan HI. Family medicine practice in Saudi Arabia: The current situation and Proposed Strategic Directions Plan 2020. J Family Community Med. 2017 Sep-Dec;24(3):156-63. http://dx.doi.org/10.4103/jfcm. JFCM_41_17. PMID:28932160

18. Alameddine M, Chamoun N, Btaiche R, El Arnaout N, Richa N, Samaha-Nuwayhid H. The workforce trends of nurses in Lebanon (2009-2014): A registration database analysis. PLoS One. 2017 Aug 11;12(8):e0182312. http://dx.doi.org/10.1371/journal.pone.o182312. PMID: 2880061

19. World health statistics 2015. Geneva: World Health Organization; 2015 (https://www.who.int/gho/publications/world_health_ statistics/2015/en/, accessed 8 January 2020).

20. El-Jardali F, Alameddine M, Dumit N, Dimassi H, Jamal D, Maalouf S. Nurses' work environment and intent to leave in Lebanese hospitals: Implications for policy and practice. Int J Nurs Stud. 2011 Feb;48(2):204-14. http://dx.doi.org/10.1016/j.ijnurstu.2010.07.009 PMID:20932524

21. El-Jardali F, Dumit N, Jamal D, Mouro G. Migration of Lebanese nurses: a questionnaire survey and secondary data analysis. Int J Nurs Stud. 2008 Oct;45(10):1490-500. http://dx.doi.org/10.1016/j.ijnurstu.2007.10.012 PMID:18242613

22. Working together for health: the World Health Report 2006. Geneva: World Health Organization; 2006 (https://www.who.int/ whr/2006/en/, accessed 8 January 2020).

23. El-Jardali F, Alameddine M, Jamal D, et al. A national study on nurses' retention in healthcare facilities in underserved areas in Lebanon. Hum Resour Health. 2013 Sep 30;11:49. http://dx.doi.org/10.1186/1478-4491-11-49 PMID:24079458

24. Hannawi S, Al Salmi I. Health workforce in the United Arab Emirates: analytic point of view. Int J Health Plann Manage. 2014 Oct-Dec;29(4):332-41. http://dx.doi.org/10.1002/hpm.2198 PMID:24114989

25. Health system profile - Jordan. Cairo: World Health Organization Regional Office for the Eastern Mediterranean Region; 2016 (http://apps.who.int/medicinedocs/documents/s17296e/s17296e.pdf, accessed 8 January 2020).

26. Boutayeb A, Helmert U. Social inequalities, regional disparities and health inequity in North African countries. Int J Equity Health. 2011 May 31;10:23. http://dx.doi.org/10.1186/1475-9276-10-23 PMID:21627818

27. Health Response Strategy Maintaining Health Security, Preserving Population Health \& Saving Children and Women Lives: a new approach 2016 \& beyond. Beirut: Ministry of Public Health; 2016 (https://www.moph.gov.lb/en/Pages/9/1269/strategic-plans\#/en/view/3447/health-response-strategy, accessed 8 January 2020). 